\title{
SEMANTICS AND SIGNIFICANCE IN EVERYDAY TALK AND PRACTICE: IS THIS CARE? AM I A CARER?
}

\author{
Sally Keeling ${ }^{1}$
}

\begin{abstract}
This paper offers an overview of global and local research and policy surrounding the formal and informal care of older people in New Zealand, alongside a commentary from an anthropological perspective. Particular attention is paid to the language of care, by exploring the ways that older people and their family carers talk about the various principles and actions which form part of 'care'. The paper thus deals with both cultural semantics, and personal meaningmaking. Then, analysis of policy documents shows contradictory definitions of the role of 'carer', while also making the case that this work is undervalued, in both the informal family field, and in the labour market generally.
\end{abstract}

Keywords: informal care; care-work; discourse; public policy

\section{INTRODUCTION}

The paper is framed within consideration of the international research language surrounding caregiving roles and experiences, alongside some recent New Zealand policy documents which open up the relationship between so-called 'formal care services' and 'informal' family-based eldercare. The paper has a particular focus on the various voices and discourses involved, both lay and professional, when considering the policy context and everyday practice in family care of older people.

Through the language surrounding extensive family engagement with older people, an anthropologist 'at home' in New Zealand today encounters many questions, an extensive vocabulary, and multiple and, at times, contradictory interpretations of the expectations and experience of family care provision. The questions posed by my title have no standard or simple answers. After a review of local and national research studies using a variety of methods to reflect on 
informal care provision to older people in a family context, the semantics and significance of family care and caring will however have been fully explored.

In the first section of this paper, I offer a brief overview of the international research literature on family and informal care, to set the scene, and pay particular attention to the international 'language of care. Then, I present perspectives from older New Zealanders themselves talking about the ways that family support, help and care is provided and received. In the third section, I review some selected New Zealand caregiving research based on the voices of family and informal carers, many of whom I have worked with, over the last twenty years or so. In the fourth section of the paper, I comment on the ways that family care is referred to and dealt with in social policy documents, including some apparently contradictory definitions. These comments return us to the notion that answering the questions posed in the title requires explicit attention to both semantics and personal meaning-making. The final section then brings together the linked fields of paid and unpaid care in an ageing society.

COSMOPOLITANISM AND CARE: NEW ZEALAND IN GLOBAL CONTEXT

The place of social support and informal care in later life has long been asserted in personal testimony, public policy, and in research in several academic disciplines, 'as a societal issue of global significance' (Yeandle et al. 2017). Global estimates converge around an estimate of eighty per cent of the help, care and support provided to older people being informal', provided by household and/ or family members, particularly, but not exclusively, by women (Fine 2006, 2007; Nolan, Davies, and Grant 2001). Formal health and social care services which make up the balance of the total 'aged care package' are thus outweighed by the informal sector, whether they are funded privately or from public sources. Such statements are clearly contingent on consistent definitions and measurements of what each of these care contributions encompasses, and what each is worth. Thus, anthropological approaches to both context and comparison are well suited to demonstrate the challenges in both local semantics and in research findings reported at an international and global level.

A key point of contention lies in the interface between the formal and informal. Estes and Swann (1992) coined the term 'no care zones' to describe the areas of aged care need in the gap between the formal and the informal in the United States. Keeling and Davey (2008) took this further in terms of its applicability to the New Zealand context, in a collection of papers exploring the 'blurred boundaries' recognised between these zones of care, in several countries, mostly English speaking, but in varied community care frameworks 
(Martin-Matthews and Phillips 2008). Further work in United Kingdom and European welfare politics questions the simplistic notions of substitution and/ or complementarity between the formal and informal sectors. For Sweden, an empirical exploration of this relationship under the title 'Either, neither, or both?' offers compelling evidence of the complexity of this interface in several different municipalities (Sundstrom, Malmberg, and Johansson 2006). In sum, they find primary evidence for both formal and informal care coming into play, as the health needs of older people increase over time, of more supplementation than substitution between the two sectors, with few examples of 'neither' as the equivalent of the 'no care zones' described earlier by Estes and Swann in the US.

The case for exploring family and social ties in old age has been strongly made by Phillipson, et al. $(1998,260)$, primarily to provide insight into how older people manage and organise their daily lives. They stress that the nature of family ties is an overt and enduring concern of social policy, especially in the field of community care (see also Chambers et al. 2009; Harper 2004). Due to structural changes affecting the family, such as smaller family size, lower fertility and increasing rates of divorce and remarriage, historical patterns and experiences cannot be simply projected into the future; nor can these be assumed as being universally played out in differing geopolitical contexts. While these authors are United Kingdom-based, many of these structural features have also been noted in New Zealand's demographic and family history as described by Pool, Dharmalingam, and Sceats (2007). Explicit United Kingdom - New Zealand comparison has been made in Thomson's (1996) work based on 'the ageing of New Zealand's welfare state' and the 'intergenerational social contract'. In the second edition of his book, Thomson further tests his thesis against concurrent United Kingdom welfare policy, with a focus on the post-war periods. The triangular relationships between individuals as they age, their families and communities, and the State, needs constant review and possible renegotiation, in the context of these evolving structural features.

It is not uncommon to find New Zealand policy statements which position population ageing as a major fiscal risk to the nation's health services: 'The financial sustainability of our healthcare system is crucial. This is especially significant given our ageing population' (Ministry of Health 2015). This quotation comes from the Associate Minister of Health announcing the overdue review of the Health of Older People Strategy (Ministry of Health 2002). Such statements bring into question the sustainability of even the notional twenty per cent publicly funded component of the overall 'care burden' apparently posed by older people. Putting this more positively, Croucher (2010) argues that geriatric medicine, the medical care of older people, is becoming the core activity of 
general hospital-based services in New Zealand. In turn, the modelling of the supply and demand projections within the informal family care sector raises questions surrounding the availability of family carers, and the extent to which they might be 'ready, willing and able' to meet rising demand and expectations, in the context of an ageing population (Goodhead and Macdonald 2007).

Within anthropology, as editor of several collections of writing on cross-cultural studies of ageing and gerontology, Sokolovsky (2009) outlined some goals for anthropological approaches to social networks and ageing. First, Sokolovsky argues that such collected work demonstrates the diverse patterns of the cultural construction of ageing in a comparative lifecourse and ethnographic perspective. This body of work focuses on empirically and ethnographically defining everyday personal networks for older people in their communities. At the same time, it elucidates the qualitative aspects and cultural meanings of kin and community networks, and their characteristics. Finally, as noted above, rapid sociocultural shifts and globalisation challenge in many ways, the structural and functional dimensions of these networks.

Research has shown that social support, and quality of interpersonal relationships, are an important element of quality of life for older people (Victor, Henderson, and Lamping 1999, 372). Further theoretical support for this generalisation comes from exchange and transaction theories, symbolic interactionism, as well as lifecourse perspectives:

There has been a notable lack of articulation between mainstream sociological theory and the work of social gerontologists.... With more rigorous and systematic integration of gerontological data with social and social psychological theory, more comprehensive explanations of life course phenomena would result. (Bengston and Dowd 1981, 55)

However, to retain the focus on care as a core component of familial relationships across the life-course, it is useful to review the work of Berkman et al. (2000) as they revisit Durkheim himself; they work through the three major levels of social facts, from the macro, through the meso to the micro.

At the macro level, sociostructural conditions are relevant, whch will be shown as I turn later (in the fourth and fifth sections of this paper) to the New Zealand public policy and national demographic features surrounding family care of older people. My purpose in these later sections is to explore the macro policy framework which surrounds family care, both explicitly and implicitly. 
In the meso level, primarily presented as the immediate social network surrounding an older person, it is clear that 'context matters'. For me as an anthropologist, this statement is both a truism, and an invitation to explore local particularity. The goal of understanding networks as 'entities', so that the life of an 'individual in context' can be located has been articulated in the life's work of another anthropologist-turned-gerontologist, Clare Wenger (beginning with Wenger 1994). Her understanding began as both holistic and longitudinal, before being applied in practice. Wenger's typology of social networks was initially derived from longitudinal fieldwork in rural and urban North Wales, before being tested in urban Liverpool. Stephens et al. (2011) have applied and tested both Wenger's network typology and the Berkman et al. (2000) model, against the patterns of other markers of social integration found in their baseline study in 2006 of mid-life New Zealanders. Cluster analysis of network data, including frequency of face-to-face contact, and non-visual contact, along with organisational participation, including affiliation to religious groups, is converted into the generation of five network types, in Wenger's method (Wenger 1994). The differentiating criteria within the network typification process are based on the relative mix of contact with kin, neighbours and friends, as well as participation in community-based groups. Geographic proximity is also included within the analytic structure. Stephens et al. (2011) also conclude that the New Zealand network-type data fits well with the Berkman et al. model of cascading effects, and confirm the value and validity of both of these approaches. The differing ways that each network type behaves in the face of evolving health needs of older people is the primary contribution of applying a network approach to the everyday situation of an older person needing care.

In contrast, there is also a strong mathematical but less commonly applied tradition, within social network research, defining and measuring the relational complexity, and mapping social network structures at the meso level: size, range, density, boundedness, proximity, homogeneity, reachability. Frankenburg's classic Communities in Britain collection (1965) directly links network characteristics to cosmopolitanism, showing how elements of network ties - reciprocity, multiplexity, duration, intimacy, density - offer insight to understanding the structure and functioning of families and communities across the urban-rural continuum. In particular, since my first encounter with an anthropological reading of Frankenburg's presentation of social network theory as an Otago undergraduate, I have found it useful and illuminating to work through the currently competing claims of universalism and local particularism, by drawing on his analysis when considering the semantics and significance of family care. 
While structural and meso-level work has been a consistent interest of anthropologists in fieldwork settings around the world, at its heart has been an assumption of geographic proximity, as a core dimension of social relationships, relevant to the provision of care. As the introduction to this issue makes clear, later interest in globalisation and cosmopolitanism has challenged this assumption, as virtual and shorter term proximity becomes more prevalent, through travel, migration, and technological links. Relating this again to how care of older family members is expressed, and experienced, has been a useful collaboration with geographers, testing prior spatial assumptions, that family care, especially of the instrumental type, would be necessarily localised. A New Zealand study explores the 'social spaces' described by older people as they locate their social ties radiating outwards from their home and neighbourhood, to the global and international scope (Wiles et al. 2009). This work deepens understanding also of how geographic distance, space and place are experienced within New Zealand's major urban context, and in the family and social worlds of older people, suggesting the further applicability of principles of 'relative distance' identified earlier in a rural setting (Keeling 2001).

Research in this meso zone (including relationships and networks of care and support) has traditionally focussed on the role of structural social support and its relationship to health and service-use outcomes. Alongside these structural dimensions of an older individual's relationships, such as the composition and extent of their social and/or support network, research interest has also been directed to functional dimensions. The content of relationships, the extent, type, sources of support and care, is both functional and pragmatic, allowing a description of 'who does what, when' to be presented.

The final level through which the analysis is explored by Berkman et al. (2000) is through pychosocial mechanisms at the micro level. Three primary pathways are outlined: health behavioral, psychological, and physiological. Alongside health behaviour, studies of help-seeking, peer pressure and peer support, social influence and adherence to health promotion programmes might all be relevant in understanding these mechanisms in the context of later life social settings.

Within the psychological or micro level, studies of perceived adequacy of support (in terms of both quality and quantity, as well as availability) is a further direction of research attention. Anthropologists will not be surprised to find that such attempts to measure satisfaction have also uncovered ambivalence and conflict arising within so-called 'supportive relationships'. The development of the term 'sandwich generation', to describe family carers who are simultaneously providing help, care and support to their ageing parents at the same time 
as they may have young adults still living in the household, and be providing regular child care for, or potentially raising, grandchildren, owes much to exchange theory, as well as to classic studies on kinship, as the earlier references to the work of people such as Bengston and Dowd and Sokolovsky show.

Just as cosmopolitanism challenges notions of space and place, cultural and linguistic analyses of the vocabulary and meanings of care are also essential. At any level of analysis (from macro to micro, from global to local) there has been a tendency to conflate two terms - care and support - as if they are synonymous. A critical paper which distinguishes the two terms both conceptually and empirically, is that by Keating et al. (2003). The paper builds on the prior extensive body of work by Wenger and others developing a network typology and uses a Canadian database to demonstrate the intensification of family involvement over time, as support networks become care networks.

\section{Help, care and support: The language of international comparison}

The fundamental acknowledgement that the 'language of care' had undergone radical semantic shifts during the twentieth century in English was expressed and developed by Bytheway and Johnson (1998) outlining the principles of linguistic and cultural change in their key paper, on the 'social construction of carers. They demonstrate that through the steps outlined as 'Recognition/ Definition/ Claims-making/ Legitimacy/ Institutionalisation' the term carer has now entered English vocabulary, with the acknowledgement that in the 1950 s the term was 'barely in the English language' (Bytheway and Johnson 1998, 241). Despite this short period, it acquired statutory and legislative use, in the UK Carers Recognition Act of 1995. This enabled the further four steps, alongside the incorporation of Carers UK, which itself followed the establishment of the Association of Carers in 1981. In this way, carers in the United Kingdom are seen as 'a category created through the interplay between personal experience and various interest groups - policy makers, researchers and pressure groups' (Bytheway and Johnson 1998, 241).

Yet, announcing Carers Week, in June 2015, the Carers UK website continues to post a similar message about the currency of the term:

You may not think of yourself as a carer - perhaps you've looked after someone for a long time without ever calling yourself one, or maybe you think the help you give your spouse or parent is simply what you should be doing. If so, you could be missing out on the help that's available to you (Carers UK 2015). 
Clearly, New Zealand and Australia have followed this linguistic line of descent, with Carers Australia and Carers NZ respectively claiming the term. Canadian patterns seem more mixed, and to follow both UK-English and AmericanEnglish patterns, with a mixed use of carer and caregiver evident in the domains of policy, research and advocacy. There is occasional use of the caregiver term in New Zealand research (see Jorgenson et al. 2010). In some situations, it can be a useful way of distinguishing provision of paid and unpaid care, by contrasting the roles of careworkers, and caregivers. In the fourth section below, I show that the continuing mixed use and meanings of these various terms is evident in New Zealand public policy documents.

The work of Forbat (2005) also adds an important perspective, in her book Talking about Care: Two Sides to the Story. In the five chapters of the book, there are five dyadic accounts of caregiving relationships, derived from a series of paired interviews. These five accounts of care illustrate clearly in narrative form, that each relationship covers a full spectrum of qualities and characteristics; one of Forbat's aims is clearly to avoid polarisation of binary locations between extremes, which are evident in both research and policy strands of work, contrasting 'care' and 'abuse', for example. Many others have also theorised contemporary care research, and included its problematic linkage with concepts of ageing and dependency (see, e.g., Fine and Glendinning 2005). A powerful public outline of 'the state of the art' in research, theory, policy and practice relating to the field of care is outlined in the inaugural editorial to the newly launched International Journal of Care and Caring (Yeandle et al. 2017).

Recently, Allen and Wiles (2013a) have used positioning theory to offer an analytic framework to some of their New Zealand research into the family contexts of older New Zealanders.

Language does things; identities are multiple and contextual; and knowledge is located in shifting stories, from the intrapersonal to the sociocultural. Positioning theorists structure the mutual effects of language (speech acts), identities (positions) and narratives (storylines), within theorised moral orders, providing ways to interpret how positioning is achieved, and how counter-positioning may be possible. Positioning analysis could be particularly interesting for the study of life transitions in older adulthood (e.g., health/disability, autonomy/dependency, home/residential care, diagnoses of neurocognitive disorders, widowhood), a large area of interest currently in gerontology. (Allen and Wiles 2013a, 175) 
In some of this work, older people without children have been participants who challenge normative expectations surrounding sources and availability of care and support in later life (Allen and Wiles 2013b).

This section has thus contributed a brief comparative overview of international research on family care in general, and informal care of older people, in several different national, cultural and political-economic contexts, across the English speaking world and research literature. From this 'etic' perspective, it has considered several different comparative contexts and processes: particular United Kingdom-New Zealand welfare comparisons (e.g., Thomson 1996) and New Zealand-Australian social policy settings such as those in aged care (Fine and Keeling 2010), various bilateral and wider research collaborations between United Kingdom, New Zealand, Australia and Canada, (Fine and Glendinning 2005; Keeling and Davey 2008; Martin-Matthews and Phillips 2008) and touched on both United States (Estes and Swann 1992) and Swedish research (Sundstrom et al. 2006). All have been chosen with a view to exploring currency, significance and contribution of the international (cosmopolitan) language of care research.

The next sections turn to the 'emic' level, to explore in turn the persectives of older people, followed by those of their family carers, drawing on both published and unpublished New Zealand research material.

NEW ZEALAND ETHNOGRAPHIC WORK WITH OLDER PEOPLE IN THEIR SOCIAL CONTEXT: OLDER PEOPLE TALK ABOUT CARE AND SUPPORT

This section will develop further some of the repertoires of talk, narratives, storylines and actions which are consistent both with positioning theory as noted above, and with local ethnographic and interview-based research with older New Zealanders.

Two New Zealand longitudinal studies of ageing can be compared, covering a span of over thirty years from mid-1980s to the present day, and set in two different regional South and North Island localities, for their ability to trace in more detail, the language and semantics of care. First, came the Mosgiel Longitudinal Study of Ageing MLSA (Campbell et al. 1994; Keeling 1998) and later, a two cohort study of the 'oldest old' Maori and non-Maori in the Bay of Plenty and midCentral North Island, known as LiLACS (Life and Living in Advanced Age: A cohort study) (Dyall et al. 2014). The approach used in both studies follows Seeman and Berkman (1988), and is aimed at understanding who provides which kinds of support, help or care. The interview framework 
in both follows a series of questions also used in the United States Macarthur studies, which deal with instrumental help with daily tasks, with emotional support, and with the availability (or not) of a 'confidante' or 'one special person', as presented in Table 1. The items listed under A, B and C also add a further supplementary question, asking if the participants 'could have used more help of this type than they received', with responses ranging from 'none at all', to 'a lot.'

Table 1. Questioning framework for help, care and support, used in New Zealand studies (MLSA and LiLACS) based on Seeman and Berkman (1988).

\begin{tabular}{|c|c|c|}
\hline Question & Response & If yes, who is that person \\
\hline $\begin{array}{l}\text { A. When you need some } \\
\text { extra help, can you count } \\
\text { on anyone to help with } \\
\text { daily tasks like grocery } \\
\text { shopping, cooking, house } \\
\text { cleaning, telephoning, } \\
\text { give you a ride? }\end{array}$ & $\begin{array}{l}\text { Yes/ } \\
\text { No/ } \\
\text { I don't need help/ } \\
\text { Refused/ } \\
\text { Don't know/ } \\
\text { Not applicable. }\end{array}$ & $\begin{array}{l}\text { In the last year, who has been most } \\
\text { helpful with these daily tasks? } \\
\text { Spouse/ Daughter/ Son/Sibling/ } \\
\text { Other relative/ Your neighbours/ } \\
\text { Co-Workers/ Church members/ } \\
\text { Club members/ Professionals/ Any } \\
\text { friend not included in these cat- } \\
\text { egories/ No-one/ Refused/ Don't } \\
\text { know/ Not applicable. }\end{array}$ \\
\hline $\begin{array}{l}\text { B. Can you count on } \\
\text { anyone to provide you } \\
\text { with emotional support? } \\
\text { (talking over problems } \\
\text { or helping you make a } \\
\text { difficult decision?) }\end{array}$ & $\begin{array}{l}\text { Yes/ } \\
\text { No/ } \\
\text { I don't need help/ } \\
\text { Refused/ } \\
\text { Don't know/ } \\
\text { Not applicable. }\end{array}$ & $\begin{array}{l}\text { Spouse/ Daughter/ Son/Sibling/ } \\
\text { Other relative/ Your neighbours/ } \\
\text { Co-Workers/ Church members/ } \\
\text { Club members/ Professionals/ Any } \\
\text { friend not included in these cat- } \\
\text { egories/ No-one/ Refused/ Don't } \\
\text { know/ Not applicable. }\end{array}$ \\
\hline $\begin{array}{l}\text { C. Is there any one special } \\
\text { person you know that } \\
\text { you feel very close and } \\
\text { intimate with - someone } \\
\text { you share confidences } \\
\text { and feelings with, } \\
\text { someone you feel you can } \\
\text { depend on? }\end{array}$ & $\begin{array}{l}\text { Yes/ } \\
\text { No/ } \\
\text { Don't know/ } \\
\text { Refused/ } \\
\text { Not applicable. }\end{array}$ & $\begin{array}{l}\text { What is this person's relationship } \\
\text { to you? } \\
\text { Spouse/ Daughter/ Son/ Brother/ } \\
\text { Sisiter/ Other relative - male/ Oth- } \\
\text { er relative - female/ Friend - male/ } \\
\text { Friend - female/ Refused/ Don't } \\
\text { know/ Not applicable }\end{array}$ \\
\hline
\end{tabular}

While these questions do allow a research focus on sources, availability and perceived adequacy of support, they are clearly designed to elicit a response based on individual norms and expectations, through the perspective of whom an older person would turn to, under everyday circumstances. Actual behaviour 
under different circumstances, such as the need for 'care in a crisis' might well reveal a different pattern. (In the same way, the definition of crisis of course is also situational, from an acute health event, to a disaster such as flooding or earthquake, but is here used to strengthen the sense of the 'everyday' in such studies of care and support.)

Alongside the epidemiological approach of the MLSA, and the extensive series of questions identifying the composition and functioning of the social and support networks of the participants, I conducted a series of extended qualitative interviews, as part of my doctoral study in anthropology (Keeling 1998). These interviews were held shortly after the nurse-administered survey questions, and invited the participants to 'talk some more about family and friends' and the roles they played in the everyday lives of the older people in this community. The analysis of these interviews was informed primarily by ethnographic principles of interpretation, but also by the work of British sociologists, such as Finch and Mason (1993), on the negotiation of family responsibilities.

Table 2 charts a series of principles which were identified within these interviews, alongside an 'emblematic phrase' which illustrates how each principle was articulated within the narrative accounts (Keeling 1998, 206-227).

Table 2. Principles and phrases negotiating help, care and support in MLSA interviews

\begin{tabular}{l|l}
\hline Principle & Emblematic phrase \\
\hline Exemption & 'They've got their own lives to lead' \\
\hline Payment & 'I'd rather pay.... \\
\hline Routinisation & 'It's not a bother' \\
\hline Surveillance & 'They keep an eye on me' \\
\hline Reciprocity & 'It's got to be give and take' \\
\hline Co-residence & 'She came to live with me' \\
\hline Compliance & 'I know it's all for my good' \\
\hline Rejection & 'I know he's doing it, so he can be satisfied' \\
\hline Privacy & 'I'm not one to be in and out of others' homes' \\
\hline Interference & 'You can't call me an interfering mother-in-law' \\
\hline Assertiveness & 'Don't you think you should have physiotherapy?' \\
\hline Friends and neighbours & 'It's nice to have someone' \\
\hline
\end{tabular}


A linking thread from these narratives is fully consistent with fundamental ethnographic understandings of psychosocial and cultural processes: that individuality and a sense of personal independence (autonomy and agency) is expressed in a social context. In the case of rejection, for example, the participant rejected her son's advice (that she should move into a retirement complex), as she saw it as driven by his own needs, not hers. These interviews designed to talk about family and friends show that a sense of self is embedded in relations with others, and while family may be central to this discourse, this is not in an exclusive sense, but is highly relative to situation and circumstances (Keeling 1999, 2001, 2003).

Despite various points of contrast with the Mosgiel study (ten years apart, Edwards as a male researcher in a Maori community in Taranaki), a second New Zealand doctoral study of the experience of positive ageing reveals interesting points of similarity in the cultural constructions of family care of Maori elders, and in the positioning of elders within their families and communities (Edwards 2009). Particular emphasis is given to the quality of family relationships, active inclusion and respect of elders, the pain of living at a distance from family members, and the strong priority given to reciprocity of care between the generations (Edwards 2009, 170ff).

In work related to that just cited, other New Zealand researchers (see Allen and Wiles 2013a, 2013b) have also challenged how older people might interpret each of these commonly used terms ('help, care and support'), starting with the claim often expressed by well-meaning professionals as 'older people need support'. In addition to mocking the likeness to a 'lady's corset' (Allen and Wiles 2009), the term support is interpreted in the vignettes and voices derived from focus groups with childless older people as 'smothering' or 'propping up' someone. Wiles (2011) further contests notions of vulnerability and dependency as markers of criteria for public legitimation of care receipt.

In summary, this section has turned to a range of ethnographic and survey based studies of ageing in New Zealand communities, seeking nuanced understandings of the ways that older people are connected to their families and communities, through linguistic strategies and cultural strands being shared, contested, and enacted in everyday actions of help, care and support. In various regional locations, the researchers presented here have worked with both English and Maori speakers to explore patterns of meaning and behaviour relating to care in later life. 
Turning to some New Zealand research projects undertaken with family carers, the discussion now turns to situations which have been explicitly designated as care relationships. Nonetheless, participants in these studies grapple with asking these two fundamental questions: Is this care? Am I a carer? These situations contrast with those in the previous section, focussed on everyday contexts, and from the point of view of older people. In several of the examples which follow, results have been published locally, only in the form of feedback to participants, or the supporting organisations involved. It is again helpful in this section to listen to the language used to describe the many and varied components of care relationships with older family members. One study participant, self-selected into an interview through her membership of a local carer support group, when asked to describe her role as a family carer, responded with the comment 'I wouldn't call it care as such', already showing that she was uneasy labelling her role as one based on care. She then proceeded to ouline the pattern of her week, and the various activities she undertook with her mother, whose care needs had recently expanded, after ceasing driving due to a major health event and not fully successful rehabilitation.

Already, this example shows that recruitment and participation matters in 'carer research, for reasons of methodology, but also because it further reinforces the circularity and at times ambiguity, embodied in the language used to talk about the subject of study: in this case, family care for and about older people (DePasquale and Moen 2017).

In the first place, it is important to consider how people become involved in such studies, and to note differences from the approach taken with older people who participated in the type of community and ethnographic studies referred to earlier. Some carers are clearly 'self-identified' in that they sign up through an online request for study participants, through a website such as Carers NZ, as in Jorgenson et al. (2010). A local carer support group in Christchurch invited researchers to conduct a survey and focus groups amongst their members (Keeling 2006a). Some respond to a national Census question, which in turn converts these citizens into 'carers' (see below, Grimmond 2014). Another commonly used technique is to include a 'screening question' within a wider study of a national sample of people of a certain age group (as in Alpass et al. 2013; Alpass and Keeling 2014).

In the 'Combining Work and Eldercare' study (Keeling and Davey 2008), a screening question was also used in a replication of an earlier United Kingdom 
workplace study. These studies follow a similarly defined screening question to seek employees who self-identified as family carers in two New Zealand local authorities who 'opted in' to the survey, and focus group components.

In some cases, a service provider in contact with an older person and family carer invites participation in a research study. A New Zealand study with carers of older people with dementia used the COPE (Carers of Older People in Europe) instrument to measure positive and negative impacts of their caregiving role (McKee et al. 2003; Roud, Keeling, and Sainsbury 2006).

Finally, family carers may be identified for a research study by the older person for whom they care, who nominates them. Caregivers of older people being assessed for home-based services were identified by the older people, and separate contact and consent was then obtained from the nominated carer, before they took part in the study. This study used standardised assessments such as COPE along with qualitative data from interviews (conducted face to face, and sometimes by telephone) (Keeling 2006b). Caregivers were identified by 160 older people being assessed for home-based services in this study, which was undertaken alongside changed assessment processes. When invited to nominate their 'main informal helper', only half (eighty-two) of the 160 older people were willing and able to do so. Then in turn, sixty-nine of these nominated carers agreed to take part in the 'caregiver's study'. Most of these (fifty-four carers) completed the COPE Index by phone, and a further fifteen took part in face to face interviews (Keeling 2006b).

This indirect recruitment method, involving 'nomination' did pose ethical and methodological issues and challenges, although considering both the quantitative and narrative data, a pattern emerges of family care which balances positive and negative features in this group of family caregivers. A majority of carers in this study reported that caregiving never caused difficulties with family, friends or finances, and that they felt well supported by health and social services.

In other words, the caregiving situation of about half of this group of older people appears to be acceptable, to both the older person and their nominated caregiver. What about the other half? An interesting finding arose from tracing the reasons given by those older people not able to nominate a caregiver. Reasons for lack of nomination were drawn from the research assessor's notes, and are estimated as split equally between four factors:

- Medically unstable/ unable to give informed consent: twelve per cent of total group 
- Did nominate, but provided incomplete/ incorrect information to contact nominated carer: twelve per cent

- Older person thought their carer (spouse, son or daughter) wouldn't be interested/ was too busy/ unavailable for some reason: twelve per cent

- Has no such person to nominate: twelve per cent.

In contrast, reports from a study of self-identified carers in New Zealand reflect higher 'caregiver strain' and low levels of satisfaction with support received (Jorgenson et al. 2010). To explain the significant variation across different carer research studies, even in New Zealand, it is vital to differentiate several types of 'family carer' roles, according to age, prior relationship, and expectations. It is also critical to consider the language used in recruitment into these studies as well as within carers' narratives themselves. Table 3 repeats the presentation of principles and phrases derived from narrative interviews with older people, this time using the common elements noted within carers' storylines, drawn from the local studies mentioned above.

Table 3. Review of principles and phrases in carers' narrative research data, from selected NZ studies.

\begin{tabular}{l|l}
\hline Principle & Emblematic phrase \\
\hline Reliance & 'She counts on me' \\
\hline Independence & 'She's really independent' \\
\hline Normalising & 'Just the usual ...' \\
\hline Convenience & 'I am the one on the spot.' \\
\hline Mutuality and reciprocity & 'We've always helped each other out' \\
\hline Simplification & 'There's a whole lot of stuff but I'll try to keep it simple.... \\
\hline
\end{tabular}

So far, I have drawn from selected research strands, to present some voices from family carers, as they seek to express their experiences within the usually private care zone of family care being provided to older people. It is possible to trace these narrative threads, in published work beginning with Opie's two books from over twenty years ago $(1991,1992)$, through to Wiles' 2003 paper mentioned earlier. In Caring Alone, (Opie 1991) the direct voices of family carers have described their sense of isolation, and distance from appropriate support services. The wider context of the interface between formal services and family care is addressed directly by both Opie (1992) and Wiles (2003), drawing, as 
seen earlier, on images of gaps, blurred boundaries and lack of clear definitions or integration between the two sectors of paid and unpaid care.

In other words, in 'talking about care' in New Zealand research studies, family carers use a wide range of alternative terms and phrases, just as in Table 2, older people themselves illustrate their reluctance to use an all-embracing term such as 'care' to describe such complexity and fluidity in the nature of their family relationships. Exploring the cultural and linguistic semantics surrounding care practices and behaviour is thus a cumulative process, seeking commonalities, and shared meanings, alongside points where definition and interpretation remain elusive, or questioned and contested. In the next section, the paper turns to fresh levels of public expression, to further extend understanding of what care means to New Zealanders, through readings of selected health and social policy documents.

NEW ZEALAND POLICY AND PUBLIC DOCUMENTS - SPEAKING A COMMON LANGUAGE?

The website for Carers NZ regularly leads with a banner heading, asking 'Are you a family carer?'

Supporting someone else may be so much a part of what you do each day that you don't see yourself as a family carer. That's fine. We're not about labels. But we are about making sure that anyone who assists a friend or family member who has extra needs due to illness, old age, or disabilities has access to support and information. (Carers NZ 2015)

In addition to producing a quarterly magazine, Family Care, and using the website effectively as a virtual meeting place for those commonly known as the invisible sector, this organisation advocates for policy development and practical support for family carers, young and old. They have also commissioned and promoted research based on New Zealand Census data since 2001.

The 2001 and 2006 Censuses shows that New Zealand's population has grown older alongside a growth in the proportion of carers, and that carers are growing older as a group. Between 2001 and 2006, the number of carers in the older age groups grew at almost double the rate of the general population. The number of carers aged 55 years and over increased by $29 \%$ between 2001 and 2006, from 96,600 older carers ( $26 \%$ of all carers), to 124,300 in 2006 (30\% of all carers). 
By contrast, the number of older persons in the general population increased by only $15 \%$ in the same time. (Department of Labour 2011)

These increases may reflect both real growth and increased public knowledge and experience of the language and practice of family care, as an update following the 2013 Census, by Grimmond shows $(2014,6)$ :

According to the Statistics New Zealand Census in 2013 there were 223,155 New Zealanders looking after a member of own household who is ill or has a disability (denoted in this report as carers of a household member) and 267,303 New Zealanders helping someone who is ill or has a disability who does not live in own household (denoted in this report as carers of a non-household member). In total there were 431,649 unpaid carers. The total number of unpaid carers is less than the sum of these two classifications as 58,809 (or $14 \%$ of unpaid carers) care for both household and non-household members. Although there has been an increase of 60,909 carers between 2001 and 2013 (i.e. a 16\% increase), this increase appears to simply reflect population growth, as in both 2001 and 2013 the number of unpaid carers represented $12.8 \%$ of the adult population of New Zealand.

Grimmond's analysis then models and imputes the economic value of this extensive amount of unpaid family care, paying particular attention to the personal and public interface between paid and unpaid (family based) care work, which has been explored in many national contexts, as shown earlier in this article. The National Health Committee (2010) also reported on this interface in terms of the public policy response to the growing call for better support for unpaid family carers. This report notes that under conditions of population ageing, a growing number of family carers are themselves aged over sixty-five, particularly those caring for their spouse. A further issue relates to the potentially conflicting policy pressure for older people to 'extend their working lives'; a worker in their sixties may well be faced with a difficult choice to reduce work commitments to facilitate increasing care needs of a spouse, or a parent aged in their eighties (Starr and Szebehely 2017).

However, it is clear that even within the language found in current policy and public documents, there are two very different definitions and interpretations of the one term, 'carer', as outlined below. In the first instance, this is clearly, albeit unusually, defined as a PAID role:

'Carers are often called health care assistants or community support 
workers, and they include those who work in residential aged care and home-based settings' (Human Rights Commission 2012, 1).

Following this definition on the opening page of the Caring Counts Report, there are about 500 uses of the term carer, signifying a paid role, in the remainder of the report, so its adoption in this work at least is clearly systematic.

In contrast, in other documents, the term 'carer' is also used to describe an UNPAID role, with or without the addition of 'family', and at times substituting 'caregiver'. The two successive New Zealand Carers Strategy documents, covering firstly 2008 to 2013 , then 2014 to 2018 , define the term carer in this way:

A carer provides care for someone close to them (family or friend) who needs help with everyday living because of a health condition, disability, or injury. In many contexts, whānau, aiga and family adopt a collective caring role. Carers' effort, understanding and compassion support people to live with dignity and participate more fully in society. (Ministry of Social Development 2014)

The Glossary to the consultation document circulated as part of the 2001 'Health of Older People Strategy' gives this definition: 'A voluntary caregiver or carer is a person, usually a family member, who looks after a person with a disability or health problem, and who is unpaid' (Ministry of Health 2001, 53).

Two years later, part of the 'Guideline for Assessment Processes for Older People', develops this definition, by referring to the opportunity for improving outcomes within the caregiving relationship:

Carers refers to all people caring for older people, including older people caring for others. Carers have particular needs resulting from their carer role, and supporting these needs results in improved outcomes for both the carer and the care recipient, including a reduction in abuse in caregiving situations (New Zealand Guidelines Group 2003, 23).

Within the New Zealand legal framework, families negotiate practical variations in care and support arrangements, according to the circumstances of all the available participants at the time. To illustrate this point, I presented two personalised family care scenarios in Keeling (2014), by drawing on the tradition of participant observation in the face of changing health needs of older family members, over relatively lengthy time scales covering around twenty 
years. These scenarios preface a collection of studies outlining the complex mix of formal and informal services and the legal and cultural dimensions surrounding care of older people in New Zealand (Diesfeld and McIntosh 2014).

This brief overview of policy definitions of the term carer is a salutary reminder of the risk of 'talking past each other' presented in local anthropological and health discourse several years ago by Metge and Laing (1978), of intra-cultural as well as cross-cultural miscommunications. Despite this risk, in general usage, it is claimed that the similarities in both language and cultural context between New Zealand and Australian research, policy and practice in the aged care sector outweigh differences, making a trans-Tasman policy comparison both possible and informative (Fine and Keeling 2010). In the same way, international comparison in both formal and informal care research (as covered in the first section of this paper), has been shown to also be legitimate, with the continuing proviso that key terms in local usage are clearly defined at the outset: the most common ones likely to pose problems in a comparative context are 'carer', and 'caregiver', and whether these connote a paid or unpaid role.

PAID AND UNPAID CARE IN AN AGEING SOCIETY - SUMMARY AND REVIEW

The previous sections have shown that the definitions and meanings surrounding paid and unpaid care of older people are at times contested, and often contradictory. This field thus demonstrates a central ambiguity inherent in studying globalisation and cosmopolitanism. Research evidence, both local and international, needs careful interpretation, along with application into New Zealand discourse, at all levels, whether in everyday language, or in the context of research and policy.

In the paid care sector and in labour market terms, global patterns of female dominance, casualisation, low pay, regional variation, and links to both national and international migration patterns are evident. Global patterns of rising demand for aged care, in particular, are driven by the notable growth of the oldest old', and the prevalence of chronic conditions and long term disability in the New Zealand population as elsewhere. In turn, ageing of the paid workforce includes the health and social care sector. This further compounds the risk that rising participation in the labour market, particularly by older men and women, and women of all ages, may well contribute to reducing the supply of informal care. Policy slogans, or strategic directions, such as 'ageing in place' in turn contribute to trends in the sites and settings of care delivery, and in preferences (Schofield et al. 2006). In New Zealand, this plays out in particular in the threshold or interface between home-based services and residential care, 
and implicates further the role and everyday work carried out by family carers.

Bowling and Grundy reviewed international evidence surrounding this interface nearly twenty years ago, concluding:

fairly strong evidence appears to exist of a relationship between social support, network structure and health status, mortality as well as risk of entry into institutional care ... there is doubt about whether the crucial variable has been measured ... [There is] tremendous potential for further research (Bowling and Grundy 1998, 359).

These latter comments continue to resonate in New Zealand research and practice up to the time of writing.

In reviewing the linguistic and social construction of 'care' and the role of 'carer' in research and practice, the evidence considered here suggests that 'care' is used or identified by an older person themself or by others, when it carries an implication of a 'threshold' of higher or increasing need. Following an implicit scale of rising intensity, intimacy, or risking sustainability, the lesser terms such as 'help and support' are more likely to be used when below this threshold. The extensive range of alternative vocabulary and phraseology, tabulated alongside a spectrum of implicit cultural principles in Tables 2 and 3 , serves to reinforce doubt as to whether the 'crucial variable' sought above, has yet been found, or indeed can be. This somewhat sliding scale of 'increasing perceived need for care' also fits within a context of historical or current familial relations, meaning that a familial role label is more likely to be used instead of carer, in the face of what is seen as a lower level of need, and where more generalised help and support might be sufficient.

Everyday family relations can in many circumstances adjust to incremental need for care, and even to occasional spikes, such as periods of acute illness. However, care in a crisis situation is commonly seen as a trigger for role adjustments in family care contexts, and equally can become professionalised when public health systems find themselves as default care providers. It is here that unpaid family care intersects critically with access to and utilisation of paid or formal care services, including primary care. Essentially, the anthropological endeavour undertaken in this chapter is aimed at making sense of the commonly taken for granted family relations surrounding care of older family members in any rapidly changing society. It requires both emic and etic perspectives, and continuous and simultaneous translation between the cosmopolitan and the local. 
NOTES

1 Sally Keeling was awarded her PhD by the Dept of Anthropology at the University of Otago in 1999, and she then spent the next two decades engaged in teaching and research based in the Dept of Medicine, University of Otago, Christchurch. Her primary field for this work has been understanding the social context of ageing in New Zealand communities, and its application into policy and service development at a national level. She has also served as an Associate Editor for Cambridge University Press, on the journal Ageing and Society since 2010.

Email: sally@keeling.co.nz

\section{REFERENCES}

Allen, R.E.S. and J.L. Wiles. 2009. 'A Type of Lady's Corset? Support for Older People'. Journal of Primary Health Care 1(2):156-157.

- 2013a. 'The Utility of Positioning Theory to the Study of Ageing: Examples from Research with Childless Older People'. Journal of Aging Studies 27: $175-187$.

- 2013b. 'Receiving Support When Older: What Makes It OK?' The Gerontologist. doi:10.1093/geront/gnto47

Alpass, F. and S. Keeling. 2014. 'Caregiving. Summary report for the New Zealand Longitudinal Study of Ageing. Palmerston North: Massey University.

Alpass, F., C. Stephens, R.Pond, B.Stephenson, S. Keeling, and A. Towers. 2013. 'The Influence of Ethnicity and Gender on Caregiver Health in Older New Zealanders'. Journal of Gerontology: Social Sciences 68 (5):783-793.

Bengston, V. and J. Dowd. 1981. 'Sociological Functionalism, Exchange Theory and Life-Cycle Analysis: A Call for More Explicit Theoretical Bridges'. Int Journal Aging Human Development 12 (1): 55-73.

Berkman, L., T. Glass, I. Brissette and T. Seeman. 2000. 'From Social Integration to Health: Durkheim in the new Millennium'. Social Science and Medicine 51: $843-857$.

Bowling, A. and E. Grundy. 1998. 'The Association between Social Networks and Mortality in Later Life'. Reviews in Clinical Gerontology 8 (4):353-361. 
Bytheway, B. and J. Johnson. 1998. 'The Social Construction of Carers'. In The Social Construction of Community Care, edited by A. Symonds and A. Kelly, 241-253. Basingstoke: MacMillan.

Campbell, A.J., W.J.Busby, M.C.Robertson, C.A. Lum, J.A. Langlois, and F.C. Morgan. 1994. 'Disease, Impairment, Disability and Social Handicap: A Community Study of People 70 Years and Over'. Disability and Rehabilitation $16: 72-79$.

Carers NZ. 2015. Accessed 4 June 2015 from http://www.carers.net.nz.

Carers UK. 2015. Accessed 9 July 2015 from http://www.carersuk.org/

Chambers, P., G. Allan, C. Phillipson, and M. Ray. 2009. Family Practices in Later Life. Bristol: Policy Press.

Croucher, M. 2010. 'Geriatric Medicine is Becoming the Core of Hospital Business'. New Zealand Medical Journal. 123 (1317):17-23. http://www.nzma.org. nz/journal/123-1317/4190/

Department of Labour. 2011. Labour Market Characteristics of Unpaid Carers - Accessed 4 June 15 from http://www.dol.govt.nz/publications/research/ characteristics-of-unpaid-carers/carers-04.asp

DePasquale, N. and P. Moen. 2017. 'Family Care Work: A Policy-Relevant Research Agenda. International Journal of Care and Caring 1 (1): 45-62.

Diesfeld, K. and I. McIntosh, eds. 2014. Elder Law in New Zealand. Wellington, NZ: Thomson Reuters.

Dyall, L., M. Kepa, R.Teh, R.Mules, S.Moyes, C.Wham, K.Hayman, M.Connolly, T. Wilkinson, S. Keeling, H.Loughline, S. Jatrana, and N.Kerse. 2014. 'Cultural and Social Factors and Quality of Life of Maori in Advanced Age. Te Puawaitanga o Nga Tapuwae Kia Ora Tonu - Life And Living in Advanced Age: A Cohort Study in New Zealand (Lilacs NZ)'. New Zealand Medical Journal 127 (1393): 62-79. http://journal.nzma.org.nz/journal/127-1393/6109/

Edwards, W.J.W. 2009. 'Taupaenui: Maori Positive Ageing'. PhD Thesis in Public Health, Massey University, Palmerston North. 
Estes, C.L. and J.H. Swann. 1992. The Long Term Care Crisis: Elders Trapped in the No-Care Zone. New York: Sage.

Finch, J. and J. Mason, eds. 1993. Negotiating Family Responsibilities. London/New York: Tavistock/Routledge.

Fine, M. 2006. A Caring Society? Care and the Dilemmas of Human Services in the 21st Century. Houndmills: Palgrave/MacMillan.

- 2007. 'Uncertain Prospects: Aged Care Policy for a Long-lived Society'. In Longevity and Social Change in Australia, edited by A. Borowski, S.Encel, and E. Ozanne, 265-295. Sydney: unsw Press.

Fine, M. and C. Glendinning, C. 2005. 'Dependence, independence, or interdependence? Revisiting the Concepts of "Care" and "Dependency". Ageing and Society 25:602-621.

Fine, M. and S. Keeling. 2010. 'Australasian Social Polices'. In Sage International Handbook of Social Gerontology, edited by C.Phillipson and D. Dannefer, 525-539. London, UK: Sage Publications Ltd.

Forbat, L. 2005. Talking about Care: Two Sides to the Story. Bristol: Policy Press.

Frankenberg, R. 1965. Communities in Britain: Social Life in Town and Country. London: Penguin Books.

Goodhead, A. and J. McDonald. 2007. 'Informal Caregivers Literature Review A report Prepared for the National Health Committee'. Wellington: Health Services Research Centre, Victoria University of Wellington. Accessed 3 June 2015 from http://nhc.health.govt.nz/publications/nhc-publications-pre-2011/ informal-caregivers-literature-review-report-prepared

Grimmond, D. 2014. 'The Economic Value and Impacts of Informal Care in New Zealand. For Carers NZ and the Carers Alliance / Infometrics. Accessed 4 June 2015 from https://cdn.auckland.ac.nz/assets/central/about/equalopportunities/information-for-staff/Informationforstaffcarersdocuments/ The\%2oeconomic\%2ovalue\%20of\%2oinformal\%2ocare\%2oin\%20New\%20 Zealand\%2oFinal\%2ocopy.pdf

Harper, S. 2004. Families in Ageing Societies: A Multi-Disciplinary Approach. Oxford, UK: University Press. 
Human Rights Commission. 2012. Caring Counts: Report of the Inquiry into the Aged Care Workforce. Wellington: Human Rights Commission. Accessed 29 November, 2017 from https://www.hrc.co.nz/files/1214/2360/8576/Caring_Counts_Report.pdf

Jorgensen, D., M. Parsons, S. Jacobs and H. Arksey. 2010. 'New Zealand Informal Caregivers and their Unmet Needs'. New Zealand Medical Journal $123(1317): 9-16$.

Keating, N., P. Otfinowski, C. Wenger, J. Fast, and L. Derksen. 2003. 'Understanding the Caring Capacity of Informal Networks of Frail Seniors: A Case for Care Networks'. Ageing and Society 23 (1):115-127.

Keeling, S. 1998. Ageing and Independence in a New Zealand Community: A Three Dimensional View. PhD Thesis in Anthropology. Dunedin: University of Otago.

- 1999. 'Ageing in (a New Zealand) Place: Ethnography, Policy and Practice'. Social Policy Journal of New Zealand 13: 95-114.

- 2001. 'Relative Distance: Ageing in Rural New Zealand'. Ageing and Society $21(5)$ : 605-619.

- 2003. 'Mystories from a Public Ethnography of Ageing and Later Life'. SITES (1):186-209.

- 2006a. Unpublished Report of Summer Studentship, 'Caring for Carers'. University of Otago, Christchurch.

- 2006b. Unpublished UORG University of Otago Research Grant report.

- 2014. 'Prologue.' In Elder Law in New Zealand, edited by K. Diesfeld, and I. McIntosh, 3-9. Wellington: Thomson Reuters.

Keeling, S. and J. Davey. 2008. 'Working Carers in New Zealand: Zones of Care and Contested Boundaries'. In Aging and Caring at the Intersection of Work and Home Life: Blurring the Boundaries, edited by A. Martin-Matthews and J. Phillips, 129-146. New York: Lawrence Erlbaum Associates/ London: Taylor and Francis Group. 
McKee, K.J., I. Philp, G. Lamura, C. Prouskas, B. Öberg, B. Krevers, L. Spazzafumo, B. Bien, C. Parker, M.R. Nolan, and K. Szczerbinska. 2003. 'The cope index-a first stage assessment of negative impact, positive value and quality of support of caregiving in informal carers of older people'. Aging \& Mental Health 7: (1):39-52.

Martin-Matthews A. and J. Phillips, eds. 2008. Aging and Caring at the Intersection of Work and Home Life: Blurring the Boundaries. New York: Lawrence Erlbaum Associates/ London: Taylor and Francis Group.

Metge, J. and P. Laing. 1978. Talking Past Each Other: Problems of Cross-cultural Communication. Wellington: Victoria University Press.

Ministry of Health. 2001. Health of Older People Strategy. Draft for consultation. Wellington: Ministry of Health.

- 2002. Health of Older People Strategy. Wellington: Ministry of Health.

- 2015. Media release, accessed 8 June 2015 - http://www.nzcphm.org.nz/ news-events/news/2015-05-12-updated-strategy-for-older-people-under-way

Ministry of Social Development. 2014. The New Zealand Carers Strategy Action Plan for 2014 to 2018. Accessed 24 August, 2018 at https://www.msd.govt.nz/ documents/about-msd-and-our-work/work-programmes/policy-development/carers-strategy/carers-strategy-2014-18.pdf.

National Health Committee. 2010. 'How Should We Care for the Carers, Now and Into the Future? Manaaki Tangata'. Accessed 3 June 2015 at http://nhc.health. govt.nz/archived-publications/nhc-publications-pre-2011/how-should-wecare-carers-now-and-future-manaaki

Nolan, M., S. Davies and G. Grant, eds. 2001. Working with Older People and their Families. Milton Keynes: Open University Press.

New Zealand Guidelines Group. 2003. 'Assessment Processes for Older People: An Evidence Based Best Practice Guideline’. Wellington: New Zealand Guidelines Group.

Opie, A. 1991. Caring Alone: Looking After the Confused Elderly at Home. Wellington: Daphne Brasell Associates Press. 
- 1992. There's Nobody There: Community Care of Confused Older People. Oxford: Oxford University Press.

Phillipson, C., M. Bernard, J. Phillips, and J.Ogg. 1998. 'The Family and Community Life of Older People: Household Composition and Social Networks in Three Urban Areas'. Ageing and Society 18:259-289.

Pool, I., A. Dharmalingam, and J. Sceats. 2007. The New Zealand Family from 1840: A Demographic History. Auckland: Auckland University Press.

Roud, H., S. Keeling, and R. Sainsbury. 2006.'Using the cope Assessment Tool with Informal Carers of People with Dementia in New Zealand'. New Zealand Medical Journal 119 (1237): 2053.

Schofield, V., J. Davey, S.Keeling, and M. Parsons. 2006. 'Ageing in Place'. In Implications of Population Ageing: Opportunities and Risks, edited by J.Boston and J.Davey, 275-306. Wellington: Victoria University of Wellington, Institute of Policy Studies.

Seeman,T.E. and L.F. Berkman. 1988. 'Structural Characteristics of Social Networks and their Relationship with Social Support in the Elderly: Who Provides Support?' Social Science and Medicine 26 (7):737-749.

Sokolovsky, J. ed. 2009. The Cultural Context of Aging: Worldwide Perspectives. Praeger, Westport: Greenwood Publishing Group.

Starr, M. and M. Szebehely. 2017. 'Working Longer, Caring Harder - The Impact of "Ageing-In-Place" Policies on Working Carers in the UK and Sweden' International Journal of Care and Caring (1):115-19.

Stephens, C., F. Alpass, A. Towers, and B. Stevenson. 2011. 'The Effects of Types of Social Networks, Perceived Social Support and Loneliness on the Health of Older People: Accounting for the Social Context'. Journal of Aging and Health 23 (6): 887-911.

Sundstrom, G., B. Malmberg. and L. Johansson. 2006. 'Balancing Family and State Care: Neither, Either or Both? The Case of Sweden'. Ageing and Society 26:767-782.

Thomson, D. 1996. Selfish Generations? How Welfare States Grow Old. 2nd ed. Cambridge UK, The White Horse Press, 2nd edition. 
Victor, C.R., L.M. Henderson, and D.L. Lamping. 1999. 'Evaluating the Use of Standardized Health Measures with Older People: The Example of Social Support'. Reviews in Clinical Gerontology 9:371-382.

Wenger, G.C. 1994. Understanding Support Networks and Community Care. Aldershot: Avebury.

Wiles, J., R.Allen, A.Palmer, K. Hayman, S. Keeling, and N.Kerse. 2009. 'Older People and their Social Spaces: A Study of Attachment to Place in Aotearoa New Zealand'. Social Science and Medicine 68: 664-671.

Wiles, J.L. 2003. 'Informal Caregivers' Experiences of Formal Support in a Changing Context'. Health and Social Care in the Community 11 (3):189-207.

Wiles, J. L. 2011. 'Reflections on Being a Recipient of Care: Vexing the Concept of Vulnerability'. Social and Cultural Geography 12 (6):573-588.

Yeandle, S., Y-C. Chou, M.Fine, M. Larkin, and A. Milne. 2017. 'Care and Caring: Interdisciplinary Perspectives on a Societal Issue of Global Significance'. International Journal of Care and Caring (1):3-26. 